\title{
La sociedad cervantina \\ (Su fundación, su espíritu, su tarea)
}

\author{
José Montero Padilla*
}

\section{EN LA CALLE DE ATOCHA}

La calle de Atocha comienza en la plaza de la Provincia y llega hasta la glorieta del Emperador Carlos V. Es una de las más importantes y tradicionales vías de la capital de España, y como una divisoria entre el Madrid céntrico y el de los barrios bajos, el que se extiende hacia el sur. La evolución de las costumbres y la transformación de la ciudad han influido también, lógicamente, en la fisonomía de la calle de Atocha, que, no obstante, conserva mucho de su carácter, animación y vitalidad anteriores. En su comienzo, en lo que es todavía plaza de la Provincia, se hallan el noble edificio del Ministerio de Asuntos Exteriores y casi a continuación un hermoso templo madrileño: el de Santa Cruz. Otras iglesias sitas en esta calle son la de San Sebastián (seguramente la de más amplia y rica tradición literaria de la capital de España), en la esquina con la calle de ese nombre, y la de San Nicolás, muy adentrada en la devoción de la Villa y Corte.

Más adelante se ensancha la calle y forma una muy animada plaza, la que tiene el nombre del escritor y premio Nobel de Literatura Jacinto Benavente, quien vivió y murió en una casa de esta calle, la número 26 actual (y había nacido muy cerca, en la casa número 27 de la calle del León). Uno de los ángulos de la plaza lo forma el teatro Calderón, uno de los más amplios y conocidos de Madrid y en el que se han sucedido espectáculos de muy diverso carácter: comedia, drama, revista, variedades... y han actuado grandes figuras

* Universidad Complutense de Madrid. 
de la escena. En él estrenó Benavente varias de sus obras: Pepa Doncel, Alfilerazos, Por ser con todos leal ser para todos traidor, El demonio fue antes ángel, Cuando los hijos de Eva no son los hijos de Adán.

Según avanza la calle ésta vuelve a ensancharse, convirtiéndose en plaza, la de Antón Martín, lugar de extraordinaria animación. Se encuentra aquí el Monumental Cinema, otro gran local escénico de Madrid con una historia importante y que ha sido - es, en ocasiones - marco de espectáculos notables: folclóricos, de revistas, de atracciones internacionales, etc. Y, asimismo, marco para la música, para actuaciones de la Orquesta Nacional (dirigida por Fernández Arbós, Argenta, Toldrá, Spiteri, Frühbeck, Cobos, etc.); de la Orquesta Sinfónica, de otras orquestas españolas y extranjeras. Los conciertos, los domingos por la mañana, en el Monumental Cinema, inolvidables para quienes a ellos han asistido, son ya historia ilustre en el desarrollo de la cultura musical de nuestra Villa y Corte.

En la última parte de la calle estuvieron la Facultad de Medicina y el Hospital de San Carlos, en grandes edificios de noble arquitectura, que otorgaban animación y singular fisonomía a la zona. Estos edificios han sido habilitados para nuevas funciones culturales y administrativas.

Abundan, a lo largo de todo este recorrido callejero, las tiendas y establecimientos de distinto carácter, los restaurantes, los bares... que proporcionan animación y bullicio a la calle, a cuyo final, frente al paseo del Prado y la glorieta de Carlos V, se encuentra el Hotel Nacional, muy conocido en Madrid.

En esta calle y como ya antes se ha recordado vivió y murió el insigne autor teatral y premio Nobel Jacinto Benavente. También en ella vivió y murió Pedro Antonio de Alarcón, gran escritor, autor de novelas como El escándalo, La Pródiga, El niño de la bola, etc., y de cuentos y narraciones breves que dan testimonio de un magnífico, excepcional narrador, así El capitán Veneno, y El carbonero alcalde, y La comendadora, y El sombrero de tres picos... La casa en la que él vivió ha desaparecido, pero en la que la ha reemplazado (número 94 actual) una placa recuerda ahora al escritor.

$\mathrm{Y}$ en esta calle de Atocha, en el número 87, tiene actualmente su sede la Sociedad Cervantina, en antiguo y reconstruido edificio, declarado monumento nacional de carácter histórico y que se alza sobre el solar donde estuvo la imprenta de Juan de la Cuesta, en la que fue impreso El ingenioso hidalgo Don Quijote de la Mancha, la universal novela de Miguel de Cervantes.

\section{LA MEMORIA DE CERVANTES: ADIOSES, MELANCOLÍA}

Cerca de este lugar, en la calle del León, que va desde la del Prado a la plaza de Antón Martín y a la calle de Atocha, vivió Cervantes, dos veces. La primera en 1610. La casa en la que habitó entonces estaba, probablemente, en el solar al que corresponde ahora el número 4 . 
Al año siguiente - 1611 - el autor del Quijote se traslada a otra vivienda en la cercana plazuela del Matute. Y de ésta, en 1614 o quizá antes, a casa sita en la calle de las Huertas. Así lo indica el propio escritor en la Adjunta a su Viaje del Parnaso, publicado en 1614: vive «en la calle de las Huertas, frontero de las casas donde solía vivir el Príncipe de Marruecos, en Madrid».

Finalmente, quizá en 1615, seguro en 1616, Miguel de Cervantes retorna a la calle del León, a casa que hace esquina a la de Francos (de Cervantes desde hace mucho tiempo), con entrada por la citada del León, muy próxima, casi frente a la que había sido su morada en $1610 .{ }^{1}$ Aquí le llega la muerte, el 22 de abril de 1616. Al día siguiente se hará el entierro. Pocos días antes había escrito la dedicatoria, al conde de Lemos, de su novela Los trabajos de Persiles y Sigismunda, a la que ya no verá impresa. Cervantes sentía que su muerte estaba cerca. Así nos lo confirman las palabras de su dedicatoria, que unen a esa certidumbre resignada melancolía y, no obstante, anhelo todavía de vivir:

Aquellas coplas antiguas, que fueron en su tiempo celebradas, que comienzan:

Puesto ya el pie en el estribo,

quisiera yo no vinieran tan a pelo en esta mi epístola, porque casi con las mismas palabras la puedo comenzar, diciendo:

Puesto ya el pie en el estribo, con las ansias de la muerte, gran señor, ésta te escribo.

Ayer me dieron la Extremaunción y hoy te escribo ésta. El tiempo es breve, las ansias crecen, las esperanzas menguan, y con todo esto, llevo la vida sobre el deseo que tengo de vivir, [...].

Otras palabras suyas, que cierran el Prólogo al Persiles, avisan premonitoriamente del adiós definitivo: «iAdiós, gracias; adiós, donaires; adiós, regocijados amigos; que yo me voy muriendo, y deseando veros presto contentos en la otra vida!».

Cervantes está poniendo los acordes finales a la sinfonía de adioses que había iniciado dos años antes en versos de su Viaje del Parnaso:

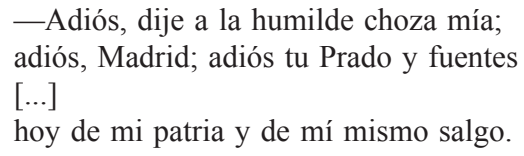

1. Véase ahora Miguel Herrero García, «Casos cervantinos que tocan a Madrid», Revista de la Biblioteca, Archivo y Museo de Madrid, 20 (1951), pp. 3-55. 
Versos los precedentes en los que pueden percibirse resonancias de otros, de Garcilaso de la Vega — tan admirado por Cervantes_- en su égloga II:

Adiós, montañas; adiós, verdes prados;

adiós, corrientes ríos espumosos:

vivid sin mí con siglos prolongados.

Sinfonía de adioses, sí, que volveremos a escuchar siglos después en un poema de Rosalía de Castro:

Adiós, ríos; adiós, fontes;

adiós, regatos pequenos;

adiós, vista dos meus ollos;

non sei cándo nos veremos.

[...]

prados, ríos, arboredas,

pinares que move o vento,

paxariños piadores,

casiña do meu contento,

$[\ldots]$

¡adiós, para sempre adiós!

Y aún más tarde resonará en versos del poema Despedida, de Luis Cernuda:

Adiós, adiós, manojos de gracias y donaires, que yo pronto he de irme, confiado, adonde, anudado el roto hilo, diga y haga

lo que aquí falta, lo que a tiempo decir y hacer aquí no supe.

Adiós, adiós, compañeros imposibles.

Que ya tan sólo aprendo

a morir, deseando

veros de nuevo, hermosos igualmente

en alguna otra vida. ${ }^{2}$

Pero, entre tantos adioses, permanecen, definitivamente inmortales, la obra y la memoria del más universal de los escritores españoles, Miguel de Cervantes, una memoria unida en este caso a unas calles, a un barrio, un barrio madrileño nombrado de los escritores.

2. Véase José Montero Reguera, «Entre tantos adioses. Una nota sobre la despedida del Persiles», Alicia Villar Lecumberri, ed., Peregrinamente peregrinos. Actas del V Congreso Internacional de la Asociación de Cervantistas (Lisboa, 1/5 de septiembre de 2003), Palma de Mallorca: Asociación de Cervantistas, 2004, vol. I, pp. 721-735. Recogido en Páginas de historia literaria, León: Universidad de León, 2009, pp. 239-248. 


\section{VuELVE EL RECUERDO DE CERVANTES: LA IMPRENTA DONDE SE IMPRIMIÓ EL QUIJOTE}

Tal como ya antes queda indicado la Sociedad Cervantina tiene su sede actualmente y desde hace varios años en la calle de Atocha, número 87, en edificio que es monumento histórico de carácter nacional, así declarado por Real Decreto de fecha 24 de julio de 1981, y en cuyo solar estuvo la imprenta de Juan de la Cuesta, donde se imprimió la Primera Parte de El ingenioso hidalgo don Quijote de la Mancha. ${ }^{3}$ En el mismo solar se fundó, en 1609, un recogimiento de niños huérfanos — de ahí la denominación de la contigua costanilla de los Desamparados - y estuvo después el «Hospitalillo del Carmen» para enfermos incurables. Esta función de hospital perduró hasta el pasado siglo XX, en que tras años de abandono del edificio que supusieron grave riesgo de demolición, las gestiones beneméritas de personas como Luis Cervera Vera, Luis Astrana Marín y Juan Antonio Cabezas consiguen salvar y que se rehabilite el edificio, ahora propiedad y sede de la Sociedad Cervantina. ${ }^{4}$ Así, pues, el solar y el edificio que sobre él se eleva, y al que nos estamos refiriendo, poseen una larga historia en la que se entremezclan y confunden distintos quehaceres, muy diversos episodios, anécdotas y recuerdos. Supo de trabajos, de afanes, del dolor humano, acaso de tormentos e inquisiciones... Y, entre tantas memorias, una singular: la de Miguel de Cervantes, que por allí anduvo, sin duda, aguardando, preguntando, preocupándose, ilusionándose y gozando con la impresión de su obra más universal.

Una obra que es también, ella misma, monumento literario cervantino y madrileño - que Madrid fue su cuna - y que está siempre, silenciosa y generosa, a nuestro alcance. Porque el Quijote es obra viva y vigente, eterna y actual. Que, si a ella nos acercamos, nos habla cálida y directa, nos da compañía y tiene, en cada instante, una palabra oportuna y verdadera para nuestra intimidad y nuestras peripecias de seres humanos. Que nos hace reír y sonreír, nos entretiene, nos regocija; nos induce a meditar y nos alecciona; que nos hará sufrir también, y experimentar, en ocasiones, toda la melancolía de un humano fracaso, e infundirá asimismo, en nosotros, la compasión, ese noble sentimiento por el que hacemos nuestro el padecer de otro para compartirlo solidaria y entrañablemente con él. Comprenderemos, en fin, que el Quijote, monumento literario, es una humanísima epopeya del hombre, del vivir del hombre, con sus grandezas y sus miserias, con sus fracasos y sus triunfos, y nos enseñará, ante todo y sobre todo, que, a despecho de codiciosos, de magos, de encantadores y de molinos de viento, los seres humanos pueden y deben reemprender cada día, con la misma intacta ilusión, la hermosa aventura de luchar por los más altos ideales: por el bien, por la libertad, por la verdad.

3. Véanse ahora los trabajos de Jaime Moll, «El taller donde se imprimió el Quijote», Voz y letra, 16, 1-2 (2005) pp. 15-22, y «Juan de la Cuesta», BRAE, LXXXV (2005), pp. 475-484; y el libro de Augusto Jurado, Juan de la Cuesta impresor del Quijote por encargo del librero Francisco de Robles y breves noticias de ambos y del autor de la obra Miguel de Cervantes, Madrid, 2007.

4. Véase Juan Antonio Cabezas, Cervantes en Madrid. Vida y muerte, Madrid: Avapies, 1990. 
Que en el Quijote está todo. Hace años, quien era entonces presidente de los Estados Unidos, Bill Clinton, quiso un día sentar a su mesa a varios destacados hombres de letras. Allí estaban, entre otros, el norteamericano William Styron, el mexicano Carlos Fuentes, el colombiano Gabriel García Márquez... A la sobremesa, la conversación derivó, lógicamente, a la política y la literatura, sobre episodios y circunstancias diversos, en torno a lecturas efectuadas... Esos días Clinton estaba leyendo un libro sobre la economía del futuro... En ese momento, García Marquéz dijo:

- Usted, señor presidente, lo que tiene que hacer es leer el Quijote, que ahí están las soluciones a todo.

\section{FUNDACIÓN Y PRIMEROS AÑOS DE LA SOCIEDAD CERVANTINA}

La Sociedad Cervantina se constituye, en Madrid, el 25 de julio, día de Santiago Apóstol, de 1953. Nace por idea y voluntad de Luis Astrana Marín, escritor ilustre y cervantista, investigador, autor de una monumental biografía: Vida ejemplar y heroica de Miguel de Cervantes Saavedra, en siete tomos. ${ }^{5} \mathrm{La}$ finalidad de la nueva entidad cultural será, tal como dice el artículo primero de sus estatutos: «fomentar el conocimiento de la vida y de las obras del inmortal autor del Quijote, Miguel de Cervantes Saavedra, y [...] difundir la Lengua y la Literatura castellanas por cuantos medios se usan para la expresión pública del pensamiento».

Previamente, y para hacer realidad proyecto tan inteligente y sugerente como ambicioso, Astrana lo expuso a un numeroso grupo de personalidades destacadas de la vida intelectual, literaria, artística y cultural española, a las que acudió para que apoyasen su proyecto y fuesen valedoras de él. Así, una vez realizados los trámites administrativos pertinentes, y redactados y aprobados los estatutos de la nueva sociedad, se reunieron aquellas personalidades con Astrana a fin de constituir la entidad y elegir la Junta directiva correspondiente. De ello queda noticia y puntual relación en el Acta correspondiente de constitución de la Sociedad Cervantina:

En la villa de Madrid, a veinticinco de julio de mil novecientos cincuenta y tres, día de Santiago, se reunen, a las doce de la mañana, los señores que se dirán, con el fin de constituir la Sociedad Cervantina, Asociación autorizada por Orden ministerial [...] en su domicilio provisional de la calle del Correo número cuatro, segundo izquierda.

5. Sobre Astrana pueden verse los trabajos de José Montero Reguera, «Luis Astrana Marín, traductor de Shakespeare y biógrafo de Cervantes», Zenón-Luis Martínez y Luis Gómez Canseco, eds., Entre Cervantes y Shakespeare: Sendas del Renacimiento, Newark, DE: Juan de la Cuesta Hispanic Monographs, 2006, pp. 113-137; y José Montero Padilla (con José Montero Reguera), Luis Astrana Marín, fundador de la Sociedad Cervantina, Cuenca: Diputación Provincial de Cuenca, 2006. 
A la reunión constituyente asistieron los componentes de la comisión organizadora, que habían llevado a cabo las gestiones previas necesarias y habían firmado la solicitud para la creación de la nueva entidad, y que serán también socios fundadores. Sus nombres y profesiones constan en la referida acta constitucional:

Luis Astrana Marín, escritor; Luis Cervera Vera, arquitecto; Ramón García García, sacerdote y párroco de la iglesia de San Marcos; Patricio González de Canales, Jefe Superior de Administración Civil; Francisco de la Vega Pérez, industrial, y Luis Astrana Martín, médico. Y siguen muchos nombres más, unos de asistentes y otros de personas no asistentes, pero que han delegado su representación en Astrana Marín. Todos serán considerados socios fundadores. Se trata, en su mayoría, de personalidades muy destacadas algunas en la vida española de entonces, como por ejemplo: Gregorio Marañón, Narciso Alonso Cortés, Arturo Duperier, Juan Ignacio Luca de Tena, Juan Pujol, Antonio Tovar, Manuel Benedito, Victorio Macho, José Castán Tobeñas, Ernesto Giménez Caballero, José Félix Huerta, Juan Antonio Cabezas, Rafael Martínez Reus, Ramón Sardinero, Manuel María de Barandica, Alfredo Escribano, Manuel de Montoliú, Rafael Láinez Alcalá, Guillermo Díaz Plaja, Luis Bardón, Bartolomé Soler, Felipe Sassone, Eduardo Aunós, Enrique Larreta, Federico Castejón, P. Félix García, José Montero Alonso, Juan Beneyto, Walter Starkie, Dionisio Gamallo Fierros, Octaviano Alonso de Celis, Antonio Vallejo-Nájera, Francisco Luque, Mariano Tomás, Aquilino Morcillo, Alberto Insúa, Walter Mangold, José de la Torre y del Cerro, Alfredo Marqueríe, Antonio S. de Larragoiti, Rafael López de Haro, María Luisa Caturla, Antonio de Obregón, Federico Romero, Antonio J. Onieva, P. Penedo, Antonio Marichalar, Juan Sedó, Ramón Ledesma Miranda, Justo García Morales, Alfonso Camín, Ignacio Aldecoa, Argimiro Torrecilla, Ricardo Rojas, Charles David Ley, etc.

Es una relación de nombres que, aun incompleta, llama la atención por su número, relieve y significación, y que, desde luego, ofrece testimonio del interés que despertaba la nueva, naciente sociedad, así como del prestigio del fundador, Luis Astrana Marín, que era capaz de convocar y atraer a tantas figuras de relieve en la existencia española de entonces.

Una vez constituida la Sociedad Cervantina, y en la misma sesión, se procedió a elegir la primera Junta directiva de la entidad, que resultó compuesta por las personas y para los cargos siguientes:

Presidente: Luis Astrana Marín; Canciller: Patricio González de Canales; Secretario general: Luis Sánchez-Brunete Álvarez; Arquitecto conservador: Luis Cervera Vera; Cronista: Juan Antonio Cabezas; Bibliotecario: Amador Porres García; Capellán: P. Ramón García y García; Tesorero: Germán Cuevas Ruiz de Castañeda; Contador: Francisco de la Vega Pérez; y Vocales: José Félix Huerta Calopa, Juan Pujol, Alberto Insúa, Rafael López de Haro, Antonio J. Onieva, Gaspar Escuder Berga, Ramón Sardinero García, Luis Astrana Martín y Eduardo Grima Cuenca.

Entre los primeros acuerdos de esta Junta directiva figura el nombramiento, como Presidente de honor de la Sociedad, de Antonio S. de Larragoiti, 
persona que apoyará mucho y generosamente las actividades de la entidad y patrocinará unos importantes premios literarios para novela, poesía y otros géneros literarios. Sin duda, sus aportaciones económicas serán esenciales en diversas ocasiones para el funcionamiento de la Sociedad Cervantina.

Asimismo, el arquitecto Luis Cervera informa ampliamente sobre las gestiones realizadas e informes que ha elaborado sobre el edificio existente en la calle de Atocha, número 85 (en el año 1953), antiguo Hospital de Hombres Incurables, cuya demolición había sido dispuesta y que Cervera ha podido evitar al hallarse parte del edificio sobre el solar donde estuvo la imprenta de Juan de la Cuesta, en la que se imprimió la Primera Parte del Quijote. Las gestiones para la salvación del inmueble continuarán a lo largo de varios años, y su éxito mediante la reconstrucción del edificio será uno de los logros más notables y significativos, hasta ahora, de la Sociedad Cervantina, y, para hacerlo posible, resultó decisiva la intervención de Luis Cervera, arquitecto ilustre, especializado en la conservación y restauración de monumentos histórico artísticos.

En las actas siguientes y hasta el fallecimiento de Luis Astrana Marín, en 1959, irá quedando constancia, muy extensa y detallada en unas ocasiones, sintética en otras, de la existencia de la Sociedad Cervantina: ideas, deseos y proyectos - muchos proyectos-, actividades y ambiciones, gestiones, más gestiones, enfados y protestas, desalientos, ignorancias y sorderas de las administraciones que - como tantas otras veces - no se enteran... pero, siempre y en cualquier caso, la constancia de un fervor cervantino auténtico y sin desmayo. Más de medio siglo después resulta, cuando menos, curioso y con frecuencia aleccionador, evocar algunos aspectos de la historia de la Sociedad Cervantina durante los años en que la presidió su fundador. También en los tiempos posteriores y hasta la hora actual.

Muchas de las sesiones de la Junta directiva se celebran, según indican las actas correspondientes, «En el domicilio provisional de la Sociedad Cervantina y en su sala de juntas, de la calle del Correo, número 4». Ese «domicilio provisional» era el particular de uno de los directivos, Patricio González de Canales, y es que la existencia de la Sociedad Cervantina se mantenía, y se seguirá manteniendo durante largo tiempo merced en gran parte a la generosidad y desprendimiento de sus directivos, socios y colaboradores.

También se da cuenta en varias actas de las altas de nuevos socios, con indicación de sus nombres, muy destacados algunos en la enseñanza, la literatura, el comercio, etc.: Francisco Sánchez Castañer y Mena, Manuel Ballesteros Gaibrois, Juan Antonio de Zunzunegui, Arturo Marasso, Carlos Romero de Lecea, José Fernández Rodríguez, John Balfour, Felipe Ximénez de Sandoval, Ricardo Majó Framis, Isabel Calvo de Aguilar, Julio Escobar, Julio Milego, Valentín Andrés Álvarez, Francisco Ayala, Luis de Armiñán.

Asimismo se informa sobre los nombramientos de socios de honor de tres ilustres mujeres: Concha Espina, Blanca de los Ríos y Mercedes Gaibrois (Acta n. ${ }^{\circ}$ 3, sesión celebrada el 12 de marzo de 1954). Y, al mes siguiente, del nombramiento de Jacinto Benavente (19 de abril, acta n. ${ }^{\circ}$ 4). Éste contesta 
con una carta en la que expresa su gratitud y se extiende en consideraciones sobre lo mucho que cabría hacer sobre el teatro de Cervantes (Acta n. ${ }^{\circ}$ 5, 31 de mayo). Acaecido poco después (el día 14 de julio de 1954) el fallecimiento del autor de Los intereses creados, se hará «constar en acta el sentimiento por la muerte de nuestro socio fundador y de honor don Jacinto Benavente, premio Nobel de Literatura, acaecido este verano, poco después de dirigirnos una carta de reconocimiento autógrafa» (Acta $n^{\circ}{ }^{\circ}$ 6, 27 de septiembre de 1954).

En las actas va quedando escrita la crónica asidua y minuciosa casi siempre de los trabajos, búsqueda de colaboraciones, propósitos y decepciones de la Junta directiva de la Sociedad Cervantina, con ideas sugerentes, casi siempre puestas en razón y a veces brillantes hasta la espectacularidad, pero que raramente se harán reales. Así, por ejemplo, la idea de publicar un boletín o revista, cuyo título sería Rocinante, pero de la que ningún número apareció. También con propuestas menudas mas no carentes de sentido, como la de que se confeccionen unas insignias de la Sociedad para solapa de caballero y alfiler para señoras... (Acta n. ${ }^{\circ}$ 9, 27 de diciembre de 1954).

Llama la atención el afán insistente y benemérito por establecer e intensificar relaciones con los países americanos de lengua hispana, mediante nombramientos de socios de honor, e incorporación de un alto número de socios hispanoamericanos, así como la abundante y frecuente correspondencia que se mantiene, y los contactos que se inician con varias embajadas en Madrid de países de Hispanoamérica... según reflejan las actas de la Sociedad Cervantina. Testimonio de este afán es una intervención del escritor Alberto Insúa en una Junta General Extraordinaria, tras haber realizado un largo viaje por diferentes lugares de la América que habla español, tal como recoge el Acta n. ${ }^{\circ} 8$ (Junta celebrada el 28 de noviembre de 1954):

[el señor Alberto Insúa] hace un vivísimo informe de las veintitantas conferencias por él pronunciadas en Río, Rosario, Córdoba, Montevideo, etc. y de las cuales ha dedicado dos a la Sociedad Cervantina. Trae una ola de renovadas amistades y de simpatías. Explica lo mucho que hemos de «cervantear» en América y cómo la obra de «papá Cervantes» que es la gran obra del alborear español, sigue viviendo actualmente, con todo su jugo, entre el público americano, a pesar de quienes pretenden encuadrarla como la obra de la Decadencia española. Cita múltiples deliciosas anécdotas y subraya la extraordinaria importancia del Descubrimiento de la Novela como nuevo género literario, que se debe a España y que es un acontecimiento tan importante para la Cultura como el Descubrimiento de América.

Parece claro que no le falta entusiasmo al escritor Alberto Insúa, novelista muy conocido y vocal de la Junta directiva de la Sociedad Cervantina.

Posteriormente —-26 de septiembre de 1955 - se hace referencia a José Rizal y al propósito de dedicar una sesión anual a la literatura de Filipinas, lo que ha dado ocasión a una amable carta del embajador de dicho país. Asimismo se da noticia de la publicación de un trabajo de José Rizal, El Consejo de 
los Dioses, con una nota preliminar de Astrana Marín, y en el acta se informa al respecto que, con esta publicación:

[...] la Sociedad inicia su labor editorial bajo el título Ediciones Sociedad Cervantina y que se ha realizado a propuesta de nuestro consocio y agregado cultural de la Embajada de Filipinas, Sr. Bantug en atención a que Rizal, en tan bello trabajo, coloca a Cervantes en la cima del Olimpo universal de las letras, y también, porque Filipinas merecen nuestra predilecta atención dada la rapidez con que se va perdiendo en las islas el empleo del idioma castellano (Acta n. $\left.{ }^{\circ} 16\right)$.

En la misma reunión — año 1955- se habló acerca del barrio llamado de las Letras o de las Musas, en el que se encuentra el lugar donde estuvo la imprenta de Juan de la Cuesta, y se comentó la posibilidad siguiente, reflejada en acta:

Por el barrio (uno de los de mayor trascendencia para la cultura mundial donde se enlazan casi todos los clásicos, con Menéndez Pelayo, Cajal y Benavente, que en él vivieron) podría trazarse un itinerario centrado en nuestra casa de Atocha (Acta n. ${ }^{\circ} 16$ ).

Habrán de pasar años para que esta sugerencia, tan puesta en razón, se haga realidad. Pero las ideas y una imaginación creadora no faltaban, ciertamente, en la entonces recién nacida Sociedad Cervantina.

\section{ECONOMÍA, INDEPENDENCIA Y EL PENACHO DE CYRANO DE BERGERAC}

En este tiempo inicial de la Sociedad Cervantina y como ya queda dicho, no faltaban, antes abundaban, las ideas, y las sugerencias plenas de sentido, y se formulaban proyectos, y los directivos de la entidad, presididos e impulsados por Astrana, trabajaban y dedicaban tiempo y esfuerzo a la entidad, y lo hacían siempre con generosidad absoluta... Pero, aun así, el dinero, algo de dinero al menos, era necesario, imprescindible para convertir en realidad y llevar adelante tantas y tan ilusionantes sugerencias, tantas posibilidades de interés para la vida cultural española... De cómo funcionaba en estos aspectos la Sociedad Cervantina, de cómo eran en ella lo que en alguna ocasión se ha denominado, con puntas de ironía, «pudibundos detalles», encontramos expresivos reflejos en las actas, donde se detalla el quehacer de la entidad, concretamente en un apartado que figura en todas ellas con el informe de tesorería, y que muestra a las claras su ajustadísima situación económica. Así, en septiembre de 1954, ese informe dice:

Don Germán Cuevas [tesorero], informa sobre el estado de las cuentas, del que resulta un saldo a favor de la Sociedad, en la cuenta corriente, impor- 
tante 5.236 ptas. con 30 cts., y a su vez que están pendientes de cobro, por el concepto de cuotas, 3.000 ptas. Don Ramón Sardinero entrega 500 ptas. y don Antonio J. Onieva 130 (Acta n. ${ }^{\circ}$ 6).

No obstante las escaseces dinerarias, en el mismo año 1954 uno de los vocales de la Junta directiva, Eduardo Aunós, propone la creación de un premio literario con el nombre de Cervantes y que sería el de mayor importancia de los existentes en España. Su dotación económica podría ser — se sugiere en la reunión de la Junta directiva - de doscientas a trescientas mil pesetas, que aportarían las editoriales madrileñas: «Este premio se concedería en octubre, y se convocaría de octubre a octubre [...] En todo caso habría de recaer en obras publicadas, y sin la más leve sombra de ningún negocio editorial. D. Rafael López de Haro estudiará esta iniciativa y presentará una ponencia» (Acta n. ${ }^{\circ}$ 7, 25 de octubre de 1954). Esta propuesta no se hará realidad hasta muchos años después, como es sabido, y no por convocatoria de la Sociedad Cervantina, pero queda evidente que las ideas y las propuestas — buenas, sugestivas, constructivas, ideas y propuestas - no faltaban.

La carencia de medios económicos impedirá también adquirir muebles y diversos objetos que son ofrecidos a la Sociedad por particulares, así «cinco puertas talladas, una colección de tallas de pasajes del Quijote, inspiradas en los dibujos de Gustavo Doré y, al parecer, de D. Mariano Benlliure (q. e. p. d.), una mesa de despacho tallada, una gran mesa de salón tallada, un armario gótico del siglo XV y varios muebles de los siglos XV y XVI, así como una gran biblioteca (estanterías de nogal tallado y volúmenes)». Imposible, absolutamente imposible la adquisición para la Sociedad Cervantina... (Acta n. ${ }^{\circ}$ 7, 25 de octubre de 1954). Y en la misma acta se recoge que «El Sr. Astrana Marín comunica que un socio está también dispuesto a ceder a la Sociedad un sillón de nogal que perteneció a Don Francisco de Quevedo, para pagar cuando se pueda y en las condiciones que la Sociedad estime». A pesar de tantas facilidades no habrá más referencias al respecto... Son, si se quiere, hechos menores, casi anecdóticos opinarán algunos, pero nos entristecen estas historias de penuria que muestran cómo objetos museables se pierden, desaparecen, cuando unas pequeñas cantidades de dinero habrían podido salvarlos. Y la recién nacida Sociedad Cervantina únicamente contaba con las modestas cuotas de sus socios y con algunas aportaciones generosas de amigos benefactores.

Pero hay algo que sí posee la Sociedad Cervantina: independencia, la cual defenderá siempre, y a la cual se hace referencia expresa en una Junta General Extraordinaria, bajo el título Relaciones con el Estado:

A pesar de la cesión del edificio de Atocha 87, que tanto agradecemos, la Sociedad es privada, libre e independiente. No percibe subvención ni ayuda alguna. Proyecta colaborar con las entidades públicas, siempre que quede salvaguardada su libertad de acción en la línea del mejor y más alto servicio a España (Acta n. ${ }^{\circ}$ 8, 28 de noviembre de 1954). 
Fácil aquí el recuerdo de las palabras que Don Quijote dirige a Sancho: «La libertad, Sancho, es uno de los más preciosos dones que a los hombres dieron los cielos; con ella no pueden igualarse los tesoros que encierra la tierra ni el mar encubre; por la libertad, así como por la honra, se puede y debe aventurar la vida, y, por el contrario, el cautiverio es el mayor mal que puede venir a los hombres».

Se tiene independencia, sí, una independencia que es como el penacho de Cyrano de Bergerac, pero se carece de dinero. Y esta carencia limitará la realización de actividades, las posibilidades de actuación. En la misma y ya referida Junta General celebrada el 28 de noviembre de 1954 un socio interviene y pregunta «si la Sociedad vive del aire y del cielo porque no tiene noticia se haya normalizado el cobro de las cuotas»...

Esta agobiada situación económica será casi una constante en la existencia de la Sociedad y sólo se aliviará, pasajeramente, con algunas subvenciones modestas, con las cuotas, bajas, que pagan y no siempre con puntualidad los socios... Y ello da motivo, en distintas ocasiones, a fundadas críticas dirigidas a las instituciones administrativas oficiales, así cuando el tesorero de la Sociedad interviene en una Junta y, tras exponer la penuria existente:

Da lectura a la carta que dirige la Subsecretaría del Ministerio de Información y Turismo contestando nuestra instancia y haciendo constar que dicho organismo no tiene nada que ver con Miguel de Cervantes. También el Sr. González de Canales informa que en la sesión de la Excma. Diputación Provincial en que se negó ayuda a Cervantes (sic), se votaron 50.000 ptas. para fomento de la cría caballar [...]» (Acta n. ${ }^{\circ}$ 16, 26 de septiembre de 1955).

Estas circunstancias, estos hechos (allá por los años cincuenta, aunque puedan referirse igualmente a fechas posteriores) hacen que se estime aún más la actitud benefactora y generosa de Antonio S. de Larragoiti, ya socio y presidente de honor de la Sociedad y a quien se acuerda entonces nombrar Presidente de honor a perpetuidad (Acta n. ${ }^{\circ}$ 17, 7 de noviembre de 1955).

\section{LOS PREMIOS LARRAGOITI}

En 1954 se convoca por vez primera el premio Larragoiti, dotado con 25.000 ptas., que han sido donadas por Antonio S. de Larragoiti, una de las personas que deberán figurar siempre en la historia de la Sociedad Cervantina por su apoyo tan generoso como desinteresado a la entidad. Esta convocatoria inicial se hace para una novela en lengua castellana y publicada en ese año. La concurrencia será numerosa y entre los concursantes que presentan originales figuran algunos autores muy destacados de esa hora literaria: Juan Antonio de Zunzunegui, Guillermo Hernández Mir, Juan Ventura Barrio, Julia Mélida, Sebastián Juan Arbó, Domingo Manfredi Cano, Felipe Ximénez de Sandoval, 
Jesús Fernández Santos, Etheria Artay, Isabel Calvo de Aguilar, Manuel Pombo Angulo, Concha Linares Becerra, José Luis Castillo Puche, Luis Antonio de Vega.

El jurado, compuesto por Luis Astrana Marín como presidente, y Gregorio Marañón, Rafael López de Haro, Alberto Insúa, Antonio J. Onieva, José Félix Huerta, Eduardo Aunós, Ramón García y García, y Amador Porres, acordó, por mayoría de votos, conceder el premio a la novela titulada La vida como es, original de Juan Antonio de Zunzunegui.

Este certamen literario convocado por la Sociedad Cervantina, siempre con el patrocinio de Antonio S. de Larragoiti, alcanzará notable difusión en todas sus convocatorias $\mathrm{y}$, sin duda, supuso una fe de vida importante para la entidad presidida por Astrana.

En 1955 el premio se convocó, con igual dotación (25.000 ptas.), para un libro de versos publicado dentro del año. Esta vez el número de concursantes fue muy elevado, entre ellos nombres importantes para la historia de la poesía española, como demuestra la relación siguiente, hecha por el orden de presentación de sus libros:

Serafín Ruiz Escobar, Tomás Salmerón, Antonio Manjón Borja, Agustín Fernández Salso, Leopoldo de Luis, Francisco Leal Insúa, J. A. Pérez del Valle, Fray Mauricio de Begoña, Rafael Llorente, Manuel Pinillos, Victoriano Gil Mateos, Tomás Preciado, Enrique Fernández, Carmen Conde, Luis M. ${ }^{a}$ Burillo, Isidro Conde, Eduardo Luis del Palacio, María Molina, Federico de Mendizábal, Carlos Palacios Miguel, Adriano del Valle, Gerardo Diego, José Luis López Mosteiro, Jesús Tomé Ramos, Manuel Álvarez Ortega, Ramón de Garciasol, Rafael Montesinos, Ángeles Villarta, José Domingo, Juana Torres Grueso, José García Nieto, Juan Ventura Barrios y Blas de Otero. Sí, no cabe duda: en esta relación se encuentran algunos de los nombres más importantes de la poesía española del siglo XX.

El 2 de febrero de 1956, el jurado, que formaba la Junta directiva en pleno de la Cervantina con la incorporación de Juan Antonio Zunzunegui como primer premio Larragoiti, resolvió, por mayoría, otorgar el premio a Gerardo Diego por su libro Amazona (Acta n. ${ }^{\circ}$ 22, 2 de febrero de 1956).

El acto público de entrega del premio se celebró dos días más tarde, en el Centro Asturiano de Madrid, sito en la calle del Arenal, número 9. En él volvían a encontrarse Luis Astrana Marín, presidente del jurado, y Gerardo Diego, que había obtenido el premio, y, con ambos, la memoria de las feroces contiendas literarias que los habían enfrentado en 1927, cuando se cumplió el tercer centenario del nacimiento de Luis de Góngora, el gran poeta barroco. No deja de ser curiosa y expresiva la reseña del acto escrita por Patricio González de Canales, como secretario de la entidad convocante del certamen, en el acta número 23 de la Sociedad Cervantina:

Abierto el acto por el Sr. Presidente, el Sr. González de Canales explica en breves palabras la institución del «Premio Larragoiti»; D. Amador Porres lee el acta de la concesión del Premio, en calidad de secretario del jurado, 
extendiéndose posteriormente en tan largas consideraciones que el Presidente se vio obligado a interrumpir, concediéndole la palabra a D. Alberto Insúa, quien hizo la presentación de rúbrica. Acto seguido D. Gerardo Diego recitó varias composiciones de su obra Amazona, y otras varias inéditas, entre grandes aplausos. Seguidamente el Sr. Presidente explicó el significado del acto, el sentido y valor del Premio, y ensalzó los méritos del gran poeta laureado. El tesorero Sr. Cuevas entregó al Sr. Astrana las 25.000 ptas. importe del Premio, en billetes del Banco de España, y éste las entregó públicamente entre grandes aplausos a D. Gerardo Diego.

Finalizado el acto público se dieron las gracias a D. Gaspar Escuder y se acordó darlas también a D. Antonio S. de Larragoiti, por su generoso donativo. También se acordó ofrecerle una cena el próximo lunes día 6 a D. Gerardo Diego.

Evidentemente las contiendas literarias habidas estaban ya muy lejos. Habían transcurrido años — casi treinta - y habían sucedido muchas cosas - una guerra civil entre ellas — . Acaso — es imposible saberlo con certeza-, a la personalidad compleja, arriscada, bondadosa en su fondo, de Astrana, le satisfizo presidir el jurado de un premio concedido a Gerardo Diego, uno de sus contrincantes en exaltadas pero antiguas polémicas literarias... ${ }^{6}$

El premio Larragoiti correspondiente al año 1956, convocado esta vez para artículos periodísticos, fue concedido por unanimidad a los presentados por Antonio de Obregón.

Al año siguiente se convocan dos premios Larragoiti, ambos con la misma dotación de 25.000 ptas.: uno para un libro de cuentos publicado dentro del año, otro para una biografía igualmente ya publicada de un personaje español. El jurado lo compondrán la Junta directiva y los escritores galardonados en los concursos anteriores: Juan Antonio de Zunzunegui, Gerardo Diego y Antonio de Obregón.

En 1957, en la víspera del día dedicado a Cervantes, se resuelven los dos certámenes, a los que, al igual que en las convocatorias precedentes, ha sido numerosa la concurrencia. El premio para biografías se otorga al profesor Rafael Láinez Alcalá por su obra Don Bernardo de Sandoval y Rojas, protector de Cervantes; y el destinado a series de cuentos, a Tomás Borrás por su colección de cuentos titulada Yo, tú, ella (Acta n. ${ }^{\circ}$ 39, 21 de abril de 1958).

La convocatoria y concesión de los premios Larragoiti continuará siendo acontecimiento destacado en la existencia de la Sociedad Cervantina y en la vida literaria española en general. En 1959 la convocatoria es para novela y poesía. En novela es premiado Torcuato Luca de Tena por la suya Edad prohibida; y en poesía Federico Muelas, por su libro de versos Apenas esto. En ambos casos el fallo es por mayoría de votos.

6. Los detalles sobre estas polémicas se hallarán en el libro de Montero Padilla y Montero Reguera ya citado, pp. 39-58. 


\section{CONMEMORACIONES CERVANTINAS Y LA CASA de Cervantes en Alcalá de Henares}

La fecha aniversario de la muerte de Cervantes (el día 22 del mes de abril, ya que el día 23 fue el del entierro, tal como demostró documentalmente Astrana) es recordada siempre por la Sociedad Cervantina desde su fundación, con mayor o menor relieve según las circunstancias - económicas, ya se sabelo permitan o aconsejen...

En abril de 1955, la conmemoración del CCCXXXIX aniversario adquiere especial relieve y se lleva a cabo con un esquema que se mantendrá ya siempre en lo esencial: misa de funeral, a las doce de la mañana, en la iglesia de San Marcos, y seguidamente acto de homenaje en la plaza de España, con ofrenda de coronas de flores ante el monumento dedicado a Cervantes en esa plaza, y discurso, que aquel año estuvo a cargo de Eduardo Aunós. Después, banquete, con un «menú cervantino».Y por la tarde, en el salón de actos del Centro Asturiano, sesión literaria, con abundancia de intervenciones que la hacen extensa, muy extensa en verdad. Constancia puntual de ello queda en el acta correspondiente, con los nombres de los intervinientes y los temas tratados con sus títulos, que fueron los siguientes:

Amador Porres (lectura de un soneto); Luis Astrana Marín («La última enfermedad de Cervantes»); Patricio González de Canales («Hacia un nuevo humanismo cervantino»); Luis de Armiñán (no se indica tema); Antonio J. Onieva («El Quijote en Rusia»); Walter Starkie («Cervantes y Shakespeare»); Juan Antonio de Zunzunegui («El monumento a Cervantes de la plaza de las Cortes se debe a José Bonaparte»); Ángel Lázaro (lectura de un soneto); Alberto Insúa («Cervantes en América»); y Rafael López de Haro, José Félix Huerta, Felipe Sassone y Luis Astrana Marín sobre «El caballero del verde gabán», como cierre del acto (Acta n. ${ }^{\circ} 13,28$ de marzo de 1955). Muy extenso, sí... Pero el esquema y el orden se mantendrá hasta nuestros días y sigue vigente, aunque muy abreviado en el número de intervenciones.

Gran interés tiene el acta $n^{\circ}{ }^{\circ} 29$, que recoge los acuerdos y deliberaciones de la Junta directiva de la Sociedad Cervantina en la sesión celebrada el día primero de octubre de 1956, en especial todo lo concerniente al estado y maltrato del patrimonio histórico y monumental de Alcalá de Henares, y de modo concreto cuanto se refiere a la casa natal de Miguel de Cervantes Saavedra. Las palabras de Astrana unen protesta, denuncia, tristeza, ante hechos, atropellos y demoliciones ya irreparables, como el derribo de la que fue casa natal del autor del Quijote, localizada por Astrana en 1941:

El Sr. Astrana protesta asimismo dando fe de cómo en visita efectuada en unión del Sr. González de Canales y del Prepósito de la Congregación del Oratorio P. Ausencio Rodríguez, vieron asombrados cómo sobre el antiguo solar de la casa totalmente demolida (y la cual se conservaba en bastante buen estado: muros, patio, escalera, galería o corredor alto, aleros, columnas, etc.) se estaba levantando un nuevo edificio de traza moderna (aunque 
de ambiente tradicional) cambiando totalmente el trazado del antiguo. Es más, se había invadido el solar contiguo que nada tenía que ver con la casa natal de Cervantes, en tanto se habían olvidado de restaurar la caballeriza (vendida el siglo pasado al propietario de la casa vecina que era lo más característico de los Cervantes, quienes mantuvieron en Alcalá la afición de los caballistas cordobeses. [...] Los tres socios protestan de que por parte de la Diputación, del Sr. Pombo Angulo o del arquitecto restaurador Sr. González Valcárcel no se haya consultado con el Sr. Astrana Marín, descubridor de esta casa. El Sr. Astrana dice que esto es igual que si el restaurador de un lienzo de Velázquez opinara que lo mejor era destruirlo para hacer otro más grande con materiales modernos y más adecuados para el uso actual.

Todavía hoy nos duele: que se habría podido salvar la casa donde nació Cervantes y no se hizo... ¿Por qué? En este género de hechos, tantas veces reiterados, se unen atropelladamente la torpeza, la prisa, la ignorancia, intereses diversos...

A finales del año 1957, en la Junta general celebrada el día 9 de diciembre, reaparece el tema de la casa de Cervantes en Alcalá de Henares y en acta se hace constar la siguiente referencia:

Día de la Provincia en Alcalá de Henares. Con motivo de celebrar la Excma. Diputación de Madrid el Día de la Provincia en Alcalá de Henares, fechas 6,7 y 8 de octubre pasado, se incluyó en el programa, entre otros actos, la inauguración de la «nueva» casa natal de Cervantes. La Sociedad Cervantina había ya hecho constar la monstruosidad que suponía derribar la casa de nuestro Príncipe de los Ingenios, adquirida por el Ayuntamiento de Alcalá a iniciativa de esta entidad, y construir una nueva. Para mostrar su desaprobación a esta profanación histórica y cultural la Sociedad negó su asistencia y colaboración a los actos de Alcalá, y, por tanto, a la inauguración de la «Casa de Cervantes». Con objeto de poner a sus socios al corriente de lo sucedido y explicar los motivos de la Sociedad Cervantina para adoptar esta decisión, fue enviada a la prensa una nota (que no se publicó por causas ajenas a la Sociedad), que copiada literalmente decía: «La Junta directiva de la Sociedad Cervantina, en sesión plenaria del día primero del corriente mes [octubre], acordó abstenerse de asistir a los actos de inauguración de la hoy derribada casa natal de Cervantes en Alcalá de Henares, descubierta por nuestro Presidente don Luis Astrana Marín, siendo entonces digno Alcalde de aquella ciudad el Excmo. Sr. Don José Félix Huerta Calopa, ilustre Vicepresidente de la misma Sociedad Cervantina.

La Junta General acuerda unirse en la protesta a la formulada por don Luis Astrana y Junta directiva (Acta n. ${ }^{\circ} 36$ ).

Tenían razón Luis Astrana y los demás directivos de la entidad, pero tropezaron, primero con la ignorancia y el atropello consumado, $\mathrm{y}$, después, con la censura que impidió la difusión de aquella nota de protesta. 


\section{LA Sociedad CERVAntina y SU FUNDAdoR}

En la Junta o Asamblea general celebrada el 19 de mayo de 1959, Patricio González de Canales propone que se nombre a Luis Astrana Marín presidente perpetuo de la Sociedad Cervantina. La propuesta es aceptada de manera unánime y entre grandes aplausos por los asistentes puestos todos en pie (Acta n. ${ }^{\circ}$ 43). Semeja como si se quisiera mimar - valga la palabra - a don Luis, endulzar un poco su existencia, no fácil ciertamente...

El acta n..$^{\circ} 44$, que corresponde a la Junta celebrada el día 8 de junio de 1959 , a las 20,30 horas, es la última que figura como presidida por Astrana Marín, si bien su firma no aparece al final de dicha acta.

El acta siguiente, la número 45, tiene la fecha de 7 de diciembre de 1959, tres días después de haberse producido el fallecimiento del presidente de la Sociedad. Ante todo «Se acuerda hacer constar en acta el profundo e inalterable sentimiento de esta Sociedad, por la muerte de su fundador, cuya memoria guardará, actualizándola con carácter permanente». Se evocan rasgos suyos y su labor al frente de la Sociedad Cervantina, y se recuerda su satisfacción y alegría cuando, recientemente, fue homenajeado en su tierra conquense.

Se da cuenta también de cómo los gastos producidos por el entierro y sepultura y que ascienden a la cantidad de 27.660 ptas., han sido abonados en su totalidad por Walter Mangold, vocal de la Junta directiva de la entidad. Asimismo se resuelve no celebrar ninguna sesión necrológica y sí se establece, a perpetuidad, en su memoria y en la de los demás socios fallecidos, una conmemoración anual, que tendrá lugar todos los días cuatro de diciembre.

Finalmente, y en tanto se resuelve por la Junta directiva lo que se estime más oportuno y conveniente, se nombran director y vicedirector respectivamente y con carácter provisional, a don Rafael López de Haro y a don Antonio J. Onieva (Acta n. ${ }^{\circ} 45,7$ de diciembre de 1959).

La Sociedad Cervantina, desde su fundación por Luis Astrana Marín en 1953, había estado unida esencial y entrañablemente a la personalidad de su fundador y primer presidente. Ahora, cuando éste acaba de fallecer, quienes habrán de conducir el rumbo de la entidad experimentan una sensación de orfandad, de profunda soledad. Pero, con el esfuerzo generoso de muchos, la Sociedad Cervantina continuará su brega y mantendrá encendida una candela de fervor literario por Cervantes y su obra, por la Lengua y la Literatura españolas.

Probablemente Astrana Marín había querido crear, con la Sociedad Cervantina, el gran cauce para impulsar y coordinar los estudios y actividades de carácter cervantista, y, también, para impedir atropellos, arbitrariedades, olvidos y desafueros (como el derribo de la casa natal de Cervantes en Alcalá de Henares) en todo lo concerniente al universo cervantino (y asimismo, algunos lo piensan — ¿maliciosamente? - para dirigir y arbitrar ese universo).

Para todo ello le faltaron medios, y acaso habilidad negociadora y de gestión y para atraer voluntades; también quizá le sobró ambición. Pero, en 
cualquier caso, de los afanes fundadores de Astrana Marín plasmados en la Sociedad Cervantina permanecen inalterables la nobleza, la actitud generosa y la ejemplaridad de su empeño. Ello ha sido realidad ilusionante después, y sigue siéndolo en los días actuales, merced a muchos apoyos y trabajos generosos, que dan testimonio de cómo una entidad cultural privada puede existir — ya más de cincuenta años - y llevar a cabo una labor eficaz, útil, rigurosa, siempre ilusionada y abierta a todos.

\section{CONTINUIDAD EN UN NUEVO TIEMPO}

No era fácil, ciertamente, reemplazar a una persona como Luis Astrana Marín, cervantista ilustre, benemérito investigador, escritor asiduo, traductor destacado cuyas versiones de las obras de Shakespeare todavía son reeditadas en la actualidad... A su fallecimiento, otro escritor y periodista, José Montero Alonso, dirá en un artículo necrológico: «Caracterizaban al eminente escritor una ardiente voluntad de trabajo, una vocación ilusionada, un ejemplar y admirable espíritu de independencia. Era un gran erudito, un infatigable rebuscador de noticias curiosas y documentos de interés literario e histórico». ${ }^{7}$

Pero hay que continuar su labor al frente de la Sociedad Cervantina. Y la voluntad de esfuerzo y las colaboraciones generosas seguirán constantes y manifiestas en las Juntas directivas que se sucederán en la entidad y en quienes las presiden a lo largo de los años y ponen su mejor afán para que la Sociedad mantenga vivos el espíritu y los propósitos que impulsaron su creación.

En esta nueva etapa, sucesivamente serán presidentes, beneméritos presidentes, Rafael López de Haro, escritor — novelista - muy conocido, incluso popular durante los años treinta, y notario, que desempeñará el cargo de presidente por breve tiempo y a quien sustituirá Antonio J. Onieva, profesor e inspector de enseñanza primaria. Éste permanecerá hasta el año 1973, en que dimite por razones de edad, y, entonces, la Junta directiva toma el acuerdo de nombrarle Presidente de Honor. Le sucede Patricio González de Canales, técnico de administración civil, funcionario de gran experiencia que estará al frente de distintos puestos de importancia en el Ministerio de Educación, persona de gran bondad, muy unida a la Sociedad Cervantina desde que ésta se fundó.

\section{La Cervantina en SU SEDE}

Y, seguidamente, el periodista y escritor Juan Antonio Cabezas, que ya venía formando parte de la directiva de la Sociedad Cervantina desde su fundación, 
pasa a ocupar la presidencia, desde 1980 y hasta su fallecimiento en 1993 (su edad iba con el siglo). En tan largo período de tiempo, Cabezas entregó su capacidad de gestión y su entusiasmo a la causa - cabría decir - de la entidad fundada por Astrana. En esos años se consiguió algo de especial importancia: la realización de las obras en el edificio de la calle de Atocha (número 87 actual), en cuyo solar estuvo la imprenta de Juan de la Cuesta, en la que se imprimió la Primera Parte del Quijote, (la Segunda lo fue en la imprenta situada en la muy cercana calle de San Eugenio). Para, al fin, llegar a ver construido el nuevo edificio, pretendido desde la hora fundacional, fueron precisas muchas, insistentes y pacientes acciones y gestiones. Entre éstas deben recordarse las llevadas a cabo por uno de los socios fundadores de la Sociedad, el arquitecto Luis Cervera Vera, que condujeron a la declaración del inmueble como monumento histórico de carácter nacional. La Dirección General de Bellas Artes del Ministerio de Cultura encomendó la realización del proyecto para la restauración del edificio al arquitecto, Joaquín Aracil, quien asimismo dirigió las obras, iniciadas en 1985 y finalizadas dos años después, y que asimismo contaron entonces con el apoyo económico de la Comunidad de Madrid, y de la Fundación Areces para el amueblamiento. La nueva construcción y sede de la Sociedad Cervantina fue inaugurada el 14 de diciembre de 1987, en solemne acto celebrado con la presidencia de los Reyes de España, don Juan Carlos I y doña Sofía, y con asistencia de numerosas autoridades.

Al fallecimiento de Juan Antonio Cabezas (1993) fue elegido unánimemente para la presidencia el profesor José Montero Padilla, catedrático de Literatura Española, quien ya era vicepresidente de la Cervantina y continuará como presidente hasta el año 2005. Con posterioridad será nombrado Presidente de Honor. Le sucederán Jesús Arribas (2005-2007) y Luis María Ansón (en el 2008).

\section{INTENSA ACTIVIDAD CULTURAL}

La Sociedad Cervantina, de acuerdo con su carácter de entidad cultural y con los fines y objetivos que le son propios, se ha propuesto en todo momento, y llevado a cabo, según sus medios se lo han permitido, una amplia y muy diversa labor cultural. Y ya desde sus comienzos y primeros años. Algunos testimonios de ello han quedado recogidos en páginas anteriores. Como, ante todo, las numerosas conmemoraciones cervantinas realizadas, de modo singular en torno a las fechas del 22 y 23 de abril de cada año. En esos días, en los que se cumple el aniversario de la muerte de Cervantes (fallecimiento el $22 \mathrm{y}$ entierro el 23), se recuerda al escritor con varias actividades a él dedicadas: por la mañana, misa en la iglesia de San Marcos, y ofrenda de coronas y discurso en la madrileña plaza de España; y, por la tarde, en el salón de actos de la Sociedad Cervantina: entrega de los premios convocados por la entidad, 
conferencias, etcétera. Son estas ocasiones que atraen el interés de numerosas personas y que cuentan con la colaboración de figuras destacadas de las letras y la cultura en general. Algunos de sus nombres, entre 1994 y 2005, años de la presidencia de José Montero Padilla, resultan elocuentes: Alonso Zamora Vicente, Eloy Benito Ruano, Manuel Seco, Manuel Alvar, Cristóbal Cuevas, Emilio Lorenzo, José María Díez Borque, Antonio Rey Hazas, Alejandro Fernández Pombo, Rafael Flórez, Luis Jiménez Martos, Antonio Lago Carballo, Pedro Laín Entralgo, Isaías Lerner, Luis Prados de la Plaza, Antonio Linage Conde, Ricardo Senabre, Alfonso de la Serna, Florencio Martínez Ruiz, etc.

Y también a Cervantes se dedican cursos, ciclos, conferencias sueltas, en los que igualmente intervienen ilustres profesores e investigadores. Y sobre el Príncipe de los Ingenios se convocan concursos de diverso carácter que pretenden estimular los trabajos de los investigadores jóvenes. Nombres de algunos de los concursantes premiados son: María Luisa Chuliá Rodrigo, Pilar García Carcedo, José Montero Reguera, María Gracia Bucalo, Amparo de Juan Bolufer, Mario Codina Bosch, Mario Crespo López, Cristina Olmeda Nicolás, José González Mas, Cristina Sánchez Tallafigo, Antonio Gutiérrez Pozo, Fernando Torres Antoñanza, José Manuel Cuesta Abad, Alexia Dotras Bravo, Luis López Valpuesta, David Ordóñez García. Varios de ellos se han incorporado más tarde como profesores a centros de enseñanza universitarios o de bachillerato y son ya figuras destacadas del cervantismo.

Estas actividades organizadas por la Sociedad Cervantina, muy frecuentes y diversas en la década final de la pasada centuria, y que pueden considerarse como de extensión o difusión cultural, han adoptado formas muy diversas: cursos, cursos monográficos, ciclos de conferencias (sobre Literatura Madrileña, Literatura de la Edad de Oro, Poesía Española actual, Teatro Español, sobre temas cervantinos como ya antes se ha relacionado y acerca de otros y diversos temas literarios, de carácter monográfico sobre determinados escritores españoles, como Azorín, Galdós, Jardiel Poncela, etc.), presentaciones de libros, coloquios, realización guiada y comentada de itinerarios a través del Barrio denominado de los Escritores, convocatoria de premios de carácter literario con los correspondientes actos de entrega, una extensa tarea, pues, fiel a uno de los objetivos fundamentales de la Sociedad, ya enunciado en el Artículo $1 .^{\circ}$, de sus Estatutos: «[...] difundir la Lengua y la Literatura castellanas por cuantos medios se usan para la expresión pública del pensamiento».

Tan amplia actividad supone también la presencia e intervenciones de profesores, escritores, periodistas, artistas, que aportan brillo, atracción y prestigio a la entidad. La simple enumeración de los nombres de algunos de ellos lo demuestra: Carlos Romero de Lecea, José Hierro, Rafael Morales, Pureza Canelo, Leopoldo de Luis, José García Nieto, Joaquín Benito de Lucas, José María Alfaro, José Gerardo Manrique de Lara, Federico Muelas, Eugenio de Nora, Rafael de Penagos, Mesa Esteban Drake, Elena Andrés, Milagros Salvador, Francisco Abad Nebot, Luis de Armiñán, José Altabella, Rosa Bobes Naves, Pedro Carrero Eras, Julia Cabezas, Teresa Barbadillo de la Fuente, Julián Moreiro, Rafael Fraguas, Hipólito Escolar Sobrino, Eduardo González 
Mercadé, Juan Cervera, Juana de José Prades, Pedro de Lorenzo, Remedios Prieto, José Montero Alonso, José Montero Padilla, José Montero Reguera, Antonio Pereira, Ramón Perales, Ricardo Senabre, Luis Antonio de Villena, Francisco Ynduráin, Enrique de Aguinaga, Jesús Arribas, Luciano García Lorenzo, Andrés Amorós, Juan Antonio Cabezas, Miguel García Posada, Álvaro Galmés de Fuentes, José Luis Castillo Puche, Elena Catena, Sabino Fernández Campo, Pablo Jauralde Pou, Pilar Palomo, José Galindo Antón, Luis Prados de la Plaza, Jorge Urrutia, y otros.

La realización de tan varia actividad ha sido ocasión también para nombrar socios de honor a ilustres personalidades que han apoyado destacadamente a la Sociedad, como Alonso Zamora Vicente, Hipólito Escolar Sobrino, José Hierro, José Montero Alonso, José Nieto Antolinos, Cristóbal Cuevas, Luis López Jiménez.

Y Presidentes de Honor de la entidad han sido nombrados, a lo largo del tiempo, Antonio S. de Larragoiti, Antonio J. Onieva, Felipe Segovia Olmo y José Montero Padilla.

\section{LOS BENEFACTORES}

En las páginas anteriores queda constancia, muy resumida, de las tareas realizadas hasta ahora por la Sociedad Cervantina. Proclamar la importancia de esas tareas, una cierta importancia al menos, parece de justicia. Máxime si se toma en consideración la carencia de medios de todo tipo que ha padecido, casi siempre, la entidad organizadora. Entonces, ¿cómo ello ha sido posible? Cabría contestar, con estricto respeto a la verdad, que la existencia de la Sociedad Cervantina ha sido, desde su nacimiento, una historia de generosidades, de múltiples generosidades. La de sus socios, que han contribuido, y contribuyen, aunque sea modestamente, con el pago de sus cuotas, a sufragar los gastos de la entidad. La de sus directivos — también socios - que han aportado y aportan siempre su tiempo y su esfuerzo, y, a veces, en algunos casos, las retribuciones u honorarios a que podrían tener derecho por algunos de los trabajos llevados cabo (Así, por ejemplo, los conferenciantes que, conocedores de la austera economía de la Cervantina, han renunciado, de manera tan generosa como sigilosa, a la retribución acordada). En fin, se trataba únicamente de ayudar a cubrir, con mayores o menores cantidades, los gastos de mantenimiento de la Sociedad Cervantina. De algunos nombres de directivos ha quedado constancia en páginas anteriores y deben recordarse con especial afecto y reconocimiento a su esfuerzo.

¿Y la Administración? ¿Las relaciones con lo que se suele llamar la Administración? Algunas ayudas ha habido. Una, importante, ha sido la restauración del edificio situado en la calle de Atocha, número 87 actual, obra a la que ya nos hemos referido. Y algunas subvenciones, aunque modestas, se han concedido a la Sociedad Cervantina, destinadas principalmente a la realización de cursos y ciclos de conferencias. Y ha habido también colaboraciones 
valiosas, como, ejemplarmente, la de la Junta Municipal de Moncloa-Aravaca, presidida por José Nieto Antolinos.

Mas en otras y no escasas ocasiones, los directivos de esta Sociedad han sentido desaliento, incluso tristeza, al comprobar la falta de interés, la ignorancia también, de algunos de los llamados altos cargos a la hora de atender a las dificultades y posibilidades a la vez de una entidad cultural como la Sociedad Cervantina. Con relación a tan lamentable realidad quien redacta estas páginas recuerda una expresiva anécdota, vivida personalmente con uno de esos altos cargos (no importan los nombres ni las denominaciones). Al exponerle diversas cuestiones, relativas todas al mundo cervantino, literario, cultural, y sugerirle algunas acciones de posible interés, se hizo referencia a la realización de unas ediciones no venales... y el alto cargo, mudo hasta ese momento, preguntó, ingenuamente: - ¿Y qué es una edición no venal?... Cabe añadir que el alto cargo ocupaba un puesto referente a los libros. No he conseguido olvidar el episodio.

Pero, y esto posee singular importancia, la Sociedad Cervantina ha contado a lo largo de sus más de cincuenta años de vida, con personas fervorosas de Cervantes y que han apoyado decisivamente a la entidad. Sus nombres deben recordarse siempre, con gratitud y como ejemplo: Antonio S. de Larragoiti, en los primeros años, y Walter Mangold, y Ramón Areces, y José Luis Aguirre de Retes, y - después- Felipe Segovia Olmo. Sus ayudas económicas han sido importantes siempre, y, en algunas ocasiones, fundamentales para el libre mantenimiento de la Sociedad. Y, también, constituyen un ejemplo. Así, en los días actuales, la voluntad inteligente de Felipe Segovia ha hecho posible un funcionamiento asiduo de la entidad, y también la adquisición de una prensa de imprimir que evoca la edición de la Primera Parte del Quijote en este lugar donde hoy tiene su sede la Sociedad Cervantina. Fruto asimismo de este apoyo ha sido el establecimiento de un acuerdo de la entidad con el Ayuntamiento de Consuegra, municipio de la provincia de Toledo, para la utilización de un molino, el denominado Espartero, para actividades y fines culturales promovidos y organizados por la Sociedad Cervantina. Este convenio, firmado el 20 de octubre de 2006, tiene una vigencia de veinte años prorrogables y responde a un afán de colaboración y extensión cultural.

\section{AlgunAs CONSIDERACIONES FINALES}

Acercarse a lo que ha sido, y debe continuar siendo la Sociedad Cervantina, es ocasión para conocer una historia que, sin énfasis vanidoso, cabe considerar, en cierto sentido, como ejemplar. Por las tareas llevadas a cabo, por la mantenida independencia. Nació inspirada por el fervor a la figura y la obra de Miguel de Cervantes. Y asimismo a la Lengua y la Literatura españolas, que son la gran riqueza artística con que contamos los españoles, una riqueza que se llama, sí, Cervantes, y Lope de Vega, y Quevedo, Gracián, Calderón 
de la Barca, Leandro Fernández de Moratín, Larra, Galdós, Valle-Inclán, Benavente, Baroja, Azorín, Juan Ramón Jiménez, García Lorca, Cernuda, Salinas... Tantos y tantos nombres insignes y españoles y universales. Ayudar a la difusión de este patrimonio ha sido el noble propósito que ha inspirado a la Sociedad Cervantina. Es una tarea no fácil pero hermosa. Y siempre atractiva. Que a ello se haya dedicado una entidad privada y muy escasa de medios materiales sorprende, casi asombra en unos tiempos poco propicios a la generosidad. Y aquí, una vez más, procede manifestar una expresión de gratitud a las personas que hicieron y hacen posible su existencia.

La Sociedad Cervantina se encuentra, tal como ya antes se ha recordado, en el lugar (madrileña calle de Atocha, número 87 actual) donde estuvo la imprenta en la que se imprimió la Primera Parte de Don Quijote de la Mancha, en un lugar, pues, fielmente evocador de Cervantes, y que podría alcanzar una significación y tener una función próximas a las que poseen la casa de Shakespeare en Stratford (sobre ella escribieron muy bellas páginas Benito Pérez Galdós y Jacinto Benavente), la casa de Goethe en Frankfurt (sobre ella Vicente de Pereda escribió páginas apasionadas), $\mathrm{y}$, sin salirnos de España, las que tienen las fundaciones y casas-museo de escritores como Lope de Vega, en Madrid; Galdós, en Las Palmas de Gran Canaria; Tomás Morales, en Moya (Gran Canaria); Rosalía de Castro, en Padrón (Coruña); Azorín, en Monóvar (Alicante); Antonio Machado, en Segovia; Wenceslao Fernández Flórez, en Cecebre (Coruña)... y otras muchas. Tal posibilidad puede constituir un reto tan singular como atrayente para los mejores afanes y el quehacer de la Sociedad Cervantina.

Recibido: 17 de junio de 2010

Aceptado: 1 de octubre de 2010

\begin{abstract}
Resumen
Desde su creación en 1953 la Sociedad Cervantina de Madrid ha desarrollado una extensa y diversa actividad cultural dirigida al mayor conocimiento y difusión de la vida y obra del autor del Quijote. En este trabajo se historia esa actividad a lo largo de más de sesenta años.
\end{abstract}

Palabras clave: Miguel de Cervantes. Sociedad Cervantina de Madrid. Historia cultural.

Title: The Sociedad Cervantina of Madrid. Its fundation, spirit, and work

\begin{abstract}
Since its foundation in 1953, the Sociedad Cervantina of Madrid has been carrying out very intensive cultural activities in order to spread the life and works of Miguel de Cervantes Saavedra. This article reviews its work during more than sixty years.
\end{abstract}

Key words: Miguel de Cervantes. Sociedad Cervantina of Madrid. Cultural Studies. 